\title{
Clinical results of proton beam therapy for elderly patients with non-small cell lung cancer
}

\author{
Takashi Ono ${ }^{1 *}$, Tatsuya Nakamura', Hisashi Yamaguchi ${ }^{1}$, Yusuke Azami ${ }^{1}$, Kanako Takayama ${ }^{1}$, Motohisa Suzuki $^{1}$, \\ Hitoshi Wada ${ }^{1}$, Yasuhiro Kikuchi ${ }^{1}$, Masao Murakami ${ }^{1}$ and Kenji Nemoto ${ }^{2}$
}

\begin{abstract}
Background: The purpose of the present study was to evaluate retrospectively the efficacy and safety of proton beam therapy for elderly patients ( $\geq 80$ years of age) with non-small cell lung cancer.

Methods: Patients diagnosed with T1-4 NO MO non-small cell lung cancer and treated with proton beam therapy between January 2009 and 2015 were recruited from our database retrospectively. Toxicity was evaluated using The Common Terminology Criteria for Adverse Events version 4.0.

Results: Thirty-five patients, including 25 (71\%) with clinically inoperable lung cancer, were administered proton beam therapy. The median age was 82 years (range: 80-87 years), and the median follow-up time was 34 months (range: 10-72 months). The median dose of proton beam therapy was 80.0 Gy relative biological effectiveness (RBE) (range: 60.0-80.0 Gy [RBE]), and all patients completed the treatments. All patients were followed for at least 23 months or until their death. The 3-year overall survival rate was $67.2 \%$ (90.0\% in patients with operable lung cancer, and $58.2 \%$ in those with inoperable lung cancer). The 3 -year local control rate was $86.5 \%$. Two patients presented with grade 2 pneumonitis. The occurrence rate of grade 2 pneumonitis was significantly correlated with a high lung V20 $(p=0.030)$, and a high mean lung dose $(p=0.030)$, and a low ratio of lung volume spared from $0.05 \mathrm{~Gy}$ (RBE) dose (total lung volume minus lung volume irradiated at least $0.05 \mathrm{~Gy}[\mathrm{RBE}]$ ) $(p=0.030$ ). However, there were no cases of grade 3 or higher radiation pneumonitis.
\end{abstract}

Conclusions: This study suggests that the proton beam therapy was feasible for elderly patients with non-small cell lung cancer and can be considered as one of the treatment choices for elderly patients with lung cancer.

Keywords: Elderly, Non-small cell lung cancer, Protons, Pneumonitis

\section{Background}

Lung cancer was the most frequently diagnosed cancer worldwide in 2012, accounting for about $13 \%$ of total cancer diagnoses [1]. It was estimated to have caused 1.6 million deaths, and resulted in 34.7 million disabilityadjusted life-years in 2013. In addition, it was the most common cause of cancer death globally, in both developing and developed countries [2].

Although early-stage lung cancer can be treated by surgery, the reduction in the respiratory function after

\footnotetext{
*Correspondence: abc1123513@gmail.com

1 Department of Radiation Oncology, Southern Tohoku Proton Therapy

Center, 7-172, Yatsuyamada, Koriyama, Fukushima, Japan

Full list of author information is available at the end of the article
}

lung resection significantly worsens the physical health and quality of life of the patients [3, 4]. Recently, many patients, including those with inoperable tumors, undergo radiotherapy such as stereotactic body radiotherapy (SBRT) [5-7], which has been shown to be as effective as resection for stage I lung cancer $[8,9]$.

In this aging society, the proportion of elderly patients being diagnosed with lung cancer is increasing. Moreover, their decreased physical ability, and the presence of comorbidities such as congestive heart failure, cerebrovascular disease, chronic pulmonary disease, and chronic renal disease impedes effective treatment. An increase in the number of comorbidities is directly correlated with increased mortality rates in patients [10]. 
An increasing number of lung cancer patients are being treated using proton beam therapy (PBT) with or without chemotherapy [11-15]. The advantage of PBT over conventional radiotherapy or SBRT using X-ray irradiation is that the former can deliver a more concentrated dose of radiation to tumors and a lower dose to normal tissue [16-18]. However, few reports have been published regarding the use of PBT in the treatment of lung cancer patients aged $\geq 80$. Thus, the purpose of the present study was to evaluate retrospectively the efficacy and safety of PBT for elderly patients with lung cancer.

\section{Methods}

\section{Ethics statement}

This retrospective study was approved by the ethics committees of our institution (approval number: D17-31). The study was conducted in accordance with the Declaration of Helsinki.

\section{Patients}

The present study included patients who were diagnosed with lung cancer and treated with PBT between January 2009 and 2015 at the Southern Tohoku Proton Therapy Center. Patients were retrospectively recruited from our database. The clinical stage of the patients' lung cancer (Union for International Cancer Control, 8th edition) was determined using computed tomography (CT) and positron emission tomography (PET)-CT. Written informed consent was obtained from all of the patients. The inclusion criteria were as follows: patients aged $\geq 80$ years when the patint received PBT; a solitary lung tumor; pathologically proven non-small cell lung cancer (NSCLC); a World Health Organization performance status of $0-2$; no lymph node metastasis; and the absence of distant other organ metastasis or other sites of uncontrolled cancer. Any patients who received concurrent chemotherapy, and those with interstitial pneumonitis were excluded. The judgment as to the operability was made by a conference of lung surgeons. All operable patients who received $\mathrm{PBT}$ refused to receive lung surgery.

\section{Proton beam therapy}

Treatment planning for PBT was based on threedimensional CT images that were taken at $2 \mathrm{~mm}$ intervals in the exhalation phase while using a respiratory gating system (Anzai Medical, Tokyo, Japan). A customindexed vacuum-lock bag was used to immobilize the patients. An XiO-M (CMS Japan, Tokyo, Japan; and Mitsubishi Electric) treatment planning system was used to calculate the dose distributions for PBT. The gross tumor volume (GTV) included the lung tumor. The clinical target volume (CTV) was defined as the GTV plus a margin of $0.5 \mathrm{~cm}$. The planning target volume
(PTV) was the CTV plus a $0.5 \mathrm{~cm}$ margin. The proton energy levels of $150 \mathrm{MeV}$ and $210 \mathrm{MeV}$ for 2-3 portals, and a spread-out Bragg peak were tuned as much as possible until the PTV was exposed to a $90 \%$ isodose of the prescribed dose. Proximal margins, distal margins, and smearing margins were calculated using strategy 2, which Moyers et al. reported [19]. The PBT system at our institute (Proton Beam System, Mitsubishi, Tokyo, Japan) used a synchrotron and a passive scattering method in which a proton beam passes a bar ridge filter, a range shifter, and a customized compensator before entering the patient. The treatment was administered during the exhalation phase using a respiratory gating system. A multileaf collimator, which consisted of 40 iron plates with a width of $3.75 \mathrm{~mm}$, and which could be formed into an irregular shape, was used. Daily front and lateral X-ray imaging was used for positioning. The PBT schedule was 66 Gy relative biological dose effectiveness (RBE) in 10 fractions over 2 weeks for peripheral lung tumors, and 80 Gy (RBE) in 25 fractions over 5 weeks for centrally located lung tumors. Patients with lung tumors that were located near the large intestine or small intestine received 60.0-79.2 Gy (RBE) in 25-33 fractions over 7 weeks.

\section{Evaluation and follow-up}

Comorbidities were evaluated as previously reported by Charlson et al. [10], and shown in the index. All patients underwent either CT or PET-CT to evaluate the initial tumor response within three months after the completion of treatment. The follow-up interval was every 1-3 months for the first year and every 3-6 months thereafter. Pneumonitis, excluding infection, was evaluated using the Common Terminology Criteria for Adverse Events version 4.0 [20].

\section{Statistical analyses}

All statistical analyses were performed using the IBM SPSS Statistics software program (version 22, SPSS Inc., Chicago, IL, USA). The overall survival (OS) time was defined as the time between the start of PBT and the time of the last follow-up examination or death. The Kaplan-Meier method and a log rank test were used to estimate the survival probability and compare survival, respectively. The relationships between the occurrence of lung toxicities and the dose volume histogram factors were examined using the Mann-Whitney $U$ test. The dosimetric factor of lung was examined in $2 \mathrm{~Gy}$ per fraction using lung alpha/beta ratio was 3.1 [21]. Lung V20 (ratio of lung volume irradiated at leaset $20 \mathrm{~Gy}$ ) and mean lung dose using a dose volume histogram. The ratio of the lung volume spared from 0.05 Gy (RBE) dose (total lung volume minus lung volume irradiated at least 0.05 Gy [RBE]) was also examined, as Tsujino et al. [22] 
reported that the lung volume speared from low irradiation dose. All $p$-values were two sided, and $p$ values of $<0.05$ were considered to indicate statistical significance.

\section{Results}

\section{Patients}

The initial study population included 78 patients aged $\geq 80$ years who had received PBT for a lung tumor. Patients were excluded from the analysis for the following reasons: lymph node metastasis $(n=28)$; distant other organ metastasis $(n=3)$; interstitial pneumonitis $(n=4)$; and absence of NSCLC pathology $(n=8)$. Thus, the characteristics of 35 patients, including 25 (71\%) with clinically inoperable NSCLC, were analyzed (Table 1). All patients completed treatments. The cohort comprised 26 men and 9 women, with a median age of 82 years (range: $80-$ 87 years). The comorbidity index of 30 patients (86\%) was $\geq 1$. The median follow-up time was 34 months (range: 10-72 months). The median dose of PBT was 80.0 Gy (range: 60.0-80.0 Gy [RBE]).

\section{Survival rate}

All patients were followed for at least 23 months or until their death. The 1-year, 2-year, and 3-year OS rates were 97.1\% (95\% CI: 91.6-100\%), 74.3\% (95\% CI: 59.8-88.8\%), and $67.2 \%$ (95\% CI: 50.3-83.3\%), respectively (Fig. 1). The median survival time was 56 months (95\% CI: 33.178.9 months). The 3-year cancer specific survival rate was 76.3\% (95\% CI: 60.4-92.2\%). Nine patients died due to lung cancer (metastasis, $n=7$; local recurrence, $n=2$ ), and 8 patients died due to other causes (another newly diagnosed cancer after PBT, $n=4$; other diseases, $n=4$ ). The 3 -year OS rate was significantly different between operable and inoperable patients ( $90 \%$ vs $58.2 \%, p=0.008$ ) (Fig. 2).

\section{Failure patterns}

The 3-year local control rate was $86.5 \%$ (95\% CI: 74.099.0\%) (Fig. 3). Four patients had local recurrence at 933 months. Two had lymph node metastasis, 6 had lung metastasis outside of the PBT field. Regarding other organ metastasis, 1 patient had liver metastasis, 1 patient had brain metastasis, and 4 had pleural dissemination.

\section{Toxicities}

There were no cases involving grade 4 or 5 toxicities after PBT treatment (Table 2). The toxicities of the 35 patients included $2(5.6 \%)$ cases of grade 2 pneumonitis, $4(11.1 \%)$ with grade 2 rib fractures, and 1 (2.8\%) with grade 3 dermatitis radiation. A high ratio of V $20(18.7 \%$ vs $10.9 \%, p=0.030)$, high dose of mean lung dose $(12.4 \mathrm{~Gy}$ vs $7.5 \mathrm{~Gy} p=0.030)$, and low ratio of lung volume spared from 0.05 Gy (RBE) dose $(62.9 \%$ vs $77.7 \%, p=0.030)$ were significantly correlated with the occurrence of grade2 pneumonia.
Table 1 The patient characteristics $(n=35)$

\begin{tabular}{|c|c|}
\hline Characteristics & \\
\hline \multicolumn{2}{|l|}{ Age (years) } \\
\hline Median (range) & $82(80-87)$ \\
\hline \multicolumn{2}{|l|}{ Gender } \\
\hline Male & $9(26 \%)$ \\
\hline Female & $26(74 \%)$ \\
\hline \multicolumn{2}{|l|}{ Performance status } \\
\hline 0 & $14(40 \%)$ \\
\hline 1 & $15(43 \%)$ \\
\hline 2 & $6(17 \%)$ \\
\hline \multicolumn{2}{|l|}{ Comorbidity index } \\
\hline 0 & $5(14 \%)$ \\
\hline 1 & $17(48.5 \%)$ \\
\hline 2 & $8(23 \%)$ \\
\hline 3 & $3(8.5 \%)$ \\
\hline 4 & $2(6 \%)$ \\
\hline \multicolumn{2}{|l|}{ Operable or inoperable } \\
\hline Operable & $10(29 \%)$ \\
\hline Inoperable & $25(71 \%)$ \\
\hline \multicolumn{2}{|l|}{ Follow-up time (months) } \\
\hline Median (range) & $34(10-72)$ \\
\hline \multicolumn{2}{|l|}{$T_{\text {category }}{ }^{a}$} \\
\hline $\mathrm{T} 1$ & $13(37 \%)$ \\
\hline $\mathrm{T} 2$ & $13(37 \%)$ \\
\hline $\mathrm{T} 3$ & $8(23 \%)$ \\
\hline $\mathrm{T} 4$ & $1(3 \%)$ \\
\hline \multicolumn{2}{|l|}{ Stage ${ }^{a}$} \\
\hline । & $21(60 \%)$ \\
\hline$\|$ & $13(37 \%)$ \\
\hline III & $1(3 \%)$ \\
\hline \multicolumn{2}{|l|}{ Tumor location } \\
\hline Right upper lobe & $4(11 \%)$ \\
\hline Right middle lobe & $2(6 \%)$ \\
\hline Right lower lobe & $8(23 \%)$ \\
\hline Left upper lobe & $14(40 \%)$ \\
\hline Left lower lobe & $7(20 \%)$ \\
\hline \multicolumn{2}{|l|}{ Histopathology } \\
\hline Squamous cell carcinoma & $17(48.5 \%)$ \\
\hline Adenocarcinoma & $17(48.5 \%)$ \\
\hline Non-small cell lung cacner & $1(3 \%)$ \\
\hline \multicolumn{2}{|l|}{ Diameter of lung tumor (mm) } \\
\hline Median (range) & $32.0(10.0-67.0)$ \\
\hline \multicolumn{2}{|l|}{ Total dose (Gy (RBE)) } \\
\hline Median (range) & $80.0(60.0-80.0)$ \\
\hline
\end{tabular}

Abbreviations: RBE relative biological dose effectiveness

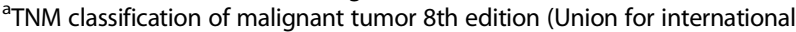
cancer contorol) 


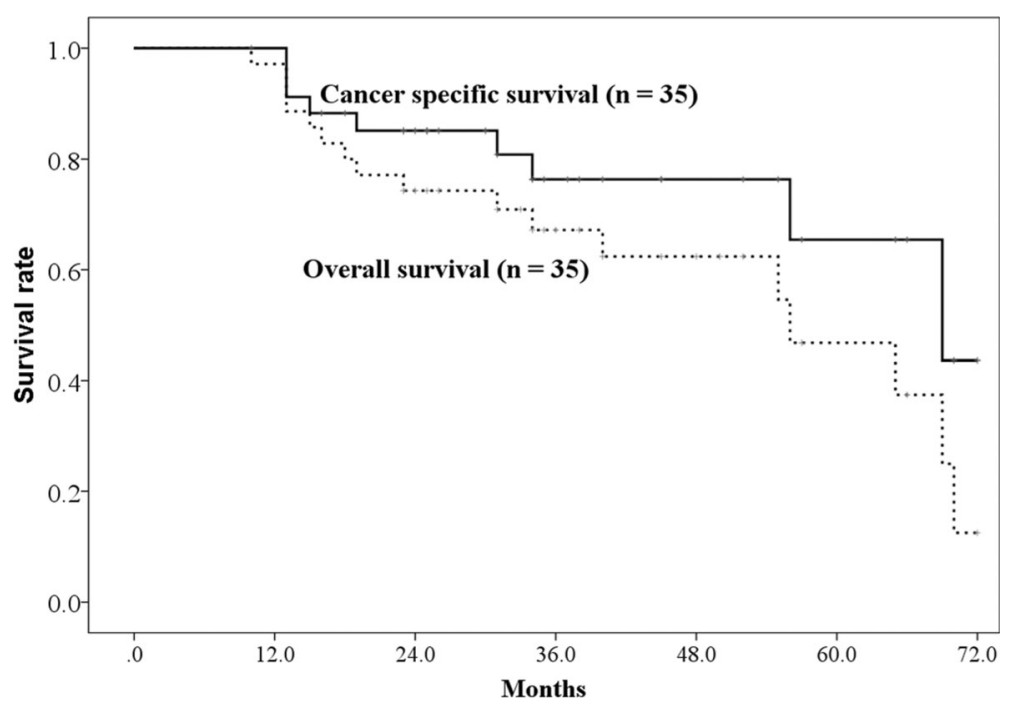

Fig. 1 The overall survival rate and disease-specific survival rate. The 3-year overall survival rates and cancer-specific survival rates were 66.7\% (95\% Cl: $50.3-83.1 \%)$ and $76.3 \%$ (95\% Cl: 60.4-92.2\%) respectively

\section{Discussion}

To the best of our knowledge, this is the first report of PBT for elderly patients ( $\geq 80$ years of age) with lung cancer. In an aging society, treatment which can reduce toxicities is particularly important because elderly patients are less able to tolerate toxicities when compared to their younger counterparts.

The SBRT was one of the treatment choices for elderly patients with lung cancer, with a 3-year OS rate was $59-83 \%$ [5-7]. The 3-year OS rate in the present study was slightly worse than in previous reports, possibly because our patient cohort was older and had larger sized tumors than previous reports. However, grade 3 or worse pneumonitis was not observed in the present study, in contrast to previous reports of a $7.7 \%$ incidence of grade 3 and 4 pneumonitis following SBRT treatment [7], and a $2.4 \%$ grade 3 pneumonitis in another study by $\mathrm{Li}$ et al. [5]. This was attributed to the ability of PBT to irradiate the malignant tissue with greater specificity than X-ray irradiation while sparing normal tissue. In fact, Barriger et al. previously reported that the mean lung dose and lung V20 were correlated with radiation pneumonitis after SBRT [23]. In the present study, we also obtained similar results when the

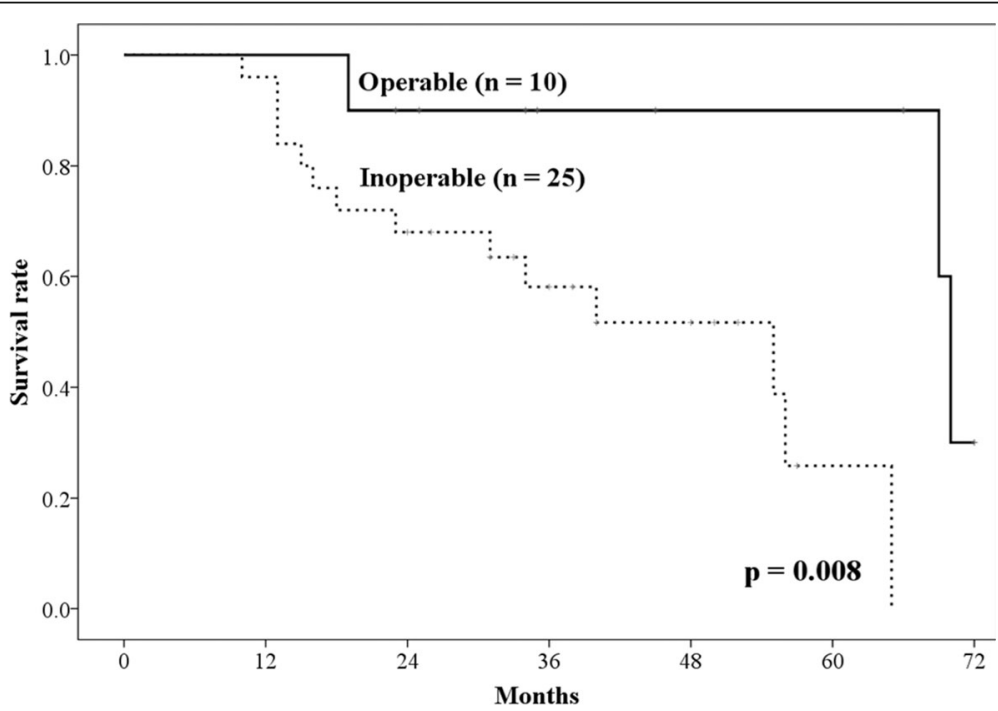

Fig. 2 The overall survival rate of patients with operable and inoperable tumors. The 3-year overall survival rates of patients with operable and inoperable tumors were $90 \%$, and $57.1 \%$, respectively $(p=0.021)$ 


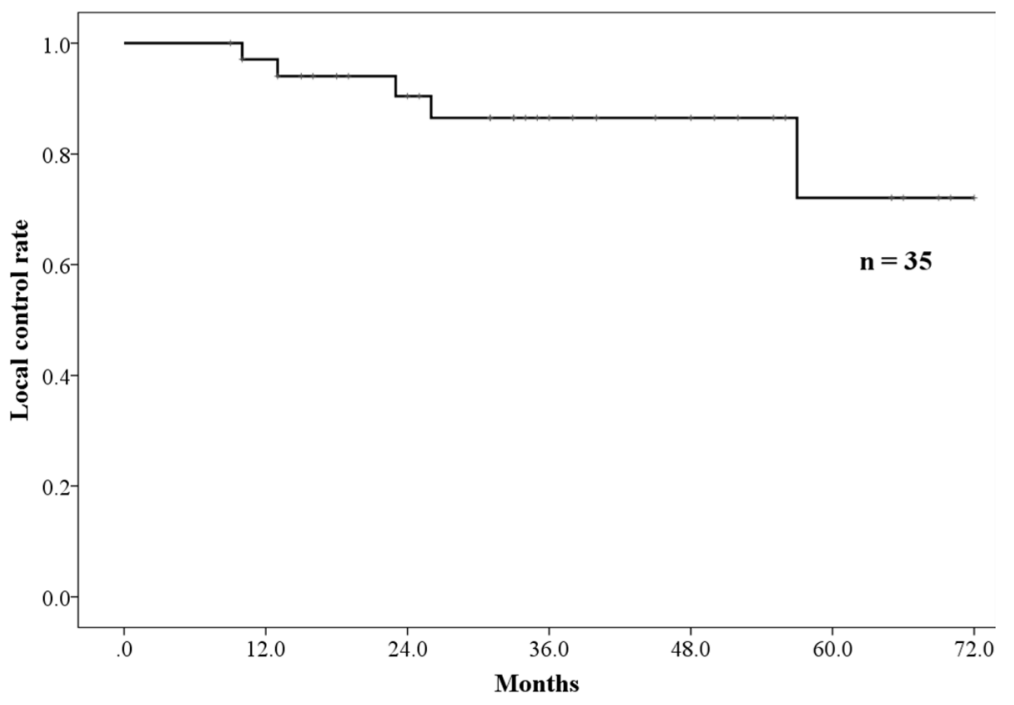

Fig. 3 The local control rates. The 3-year local control rate was $85.7 \%$ (95\% Cl: 72.0-99.4\%)

biological effective dose adjusted. Moreover, the low ratio of lung volume spared from 0.05 Gy (RBE) dose was correlated with occurrence of pneumonia in the present study. Regarding the dose volume with SBRT versus that with PBT for early lung cancer, Kadoya et al. reported that the PBT dosage was able to be significantly reduced compared with SBRT [16]. This suggests tha PBT can deliver the same dose while sparing more normal lung volume from irradiation than SBRT, which may lead to a lower occurrence rate of pneumonia and safer treatment relative to SBRT, even in elderly patients.

For elderly patients, lung resection, including lobectomy, is also a treatment choice for lung cancer. A comparison of SBRT and lung resection showed that the OS of patients receiving surgery was better than that of those receiving SBRT in an unadjusted population [24-26]. One reason for this may be that patients receiving SBRT tended to be significantly older and had lower OS. In fact, Paul et al. reported that the OS in the SBRT group with $\leq 2 \mathrm{~cm}$ lung tumors was the same as that of the surgery group in a propensity score matched analysis [26]. In contrast, Shirvani et al. on comparing five treatment strategies in elderly NSCLC patients using a propensity score matched analysis reported that the survival of all patients who received SBRT was similar to that of patients who

Table 2 Toxicities

\begin{tabular}{llllll}
\hline Toxicities & Grade 0 & Grade 1 & Grade 2 & Grade 3 & Grade 4/5 \\
\hline Pneumonitis & $2(6 \%)$ & $31(88 \%)$ & $2(6 \%)$ & 0 & 0 \\
Rib fracture & $26(74 \%)$ & $5(14 \%)$ & $4(12 \%)$ & 0 & 0 \\
Dermatitis radiation & $5(14 \%)$ & $22(63 \%)$ & $7(20 \%)$ & $1(3 \%)$ & 0 \\
\hline
\end{tabular}

underwent lobectomy [25]. Their report also found that early mortality of elderly patients was the lowest in the SBRT group. As mentioned previously, PBT treatment irradiates less of the normal lung than SBRT. This suggests that PBT for elderly patients may achieve even lower mortality rates than SBRT and surgery, although no studies to date of have directly compared the effect of PBT with other treatment options.

The 2-year OS of PBT for early stage lung cancer was previously reported to be $31-80 \%[11,13,14]$. The OS rate in the present study was not marked worse than in those previous reports, even though our patient cohort only comprised of elderly patients. This suggests that PBT for elderly patients ( $\geq 80$ years of age), including those with inoperable cancer, is as feasible and effective as in younger lung cancer patients.

Degradation of the Bragg peak occurs when PBT is performed for lung cancer [27]. To check the areas irradiated by the proton beam, PET-CT was conducted after PBT. Changing the treatment plan was not needed in any patients based on PET-CT findings in our institution.

This study had several limitations, including the small sample size and the retrospective design. However, as only a few reports have described PBT treatment in elderly lung cancer patients, we believe that the results of the present study are essential and warrant further research.

\section{Conclusions}

These findings suggest that PBT for elderly patients with NSCLC is feasible, and can be considered as one of the treatment choices for elderly lung cancer patients. 


\section{Abbreviations}

CT: Computed tomography; CTV: Clinical target volume; GTV: gross tumor volume; NSCLC: Non-small cell lung cancer; OS: Overall survival; PBT: Proton beam therapy; PET: Positron emission tomography; PTV: Planning target volume; RBE: Relative biological effectiveness; SBRT: Stereotactic body radiotherapy

\section{Acknowledgements}

We thank all staff of the Radiation Oncology section.

\section{Funding}

Present study did not receive any funding.

\section{Availability of data and materials}

The data was not shared because our institutional ethics committee did not allow it.

\section{Authors' contributions}

Each author participated sufficiently in the work. TO, MM, and TN designed the study and wrote the manuscript. HY, MS, and YA designed and implemented the treatments. KT and HW helped collect the data. YK helped with writing the manuscript. KN supervised the study. All authors have read and approved of the final manuscript.

\section{Ethics approval and consent to participate}

We obtained general informed consent for the research from patients. Present retrospective study was approved by the ethics committees of our institution (approval number: D17-31). The study was conducted in accordance with the Declaration of Helsinki.

\section{Consent for publication}

We obtained written informed consent to publish from patients.

\section{Competing interests}

The authors declare that they have no competing interests.

\section{Publisher's Note}

Springer Nature remains neutral with regard to jurisdictional claims in published maps and institutional affiliations.

\section{Author details}

'Department of Radiation Oncology, Southern Tohoku Proton Therapy Center, 7-172, Yatsuyamada, Koriyama, Fukushima, Japan. ${ }^{2}$ Department of Radiation Oncology, Yamagata University Faculty of Medicine, 2-2-2, lida-Nishi, Yamagata, Japan.

Received: 28 November 2017 Accepted: 31 January 2018 Published online: 05 February 2018

\section{References}

1. Torre LA, Bray F, Siegel RL, Ferlay J, Lortet-Tieulent J, Jemal A. Global cancer statistics, 2012. CA Cancer J Clin. 2015;65(2):87-108.

2. Fitzmaurice C, Dicker D, Pain A. The global burden of cancer 2013. JAMA Oncol. 2015;1(4):505-27.

3. Nakahara K, Monden Y, Ohno K, Miyoshi S, Maeda H, Kawashima Y. A method for predicting postoperative lung function and its relation to postoperative complications in patients with lung cancer. Ann Thorac Surg. 1985;39(3):260-5.

4. Schwartz RM, Yip R, Olkin I, Sikavi D, Taioli E, Henschke C. Impact of surgery for stage IA non-small-cell lung cancer on patient quality of life. J Community Support Oncol. 2016;14(1):37-44.

5. Li Q, Swanick CW, Allen PK, Gomez DR, Welsh JW, Liao Z, et al. Stereotactic ablative radiotherapy (SABR) using $70 \mathrm{~Gy}$ in 10 fractions for non-small cell lung cancer: exploration of clinical indications. Radiother Oncol. 2014;112(2):256-61.

6. Nagata Y, Takayama K, Matsuo Y, Norihisa Y, Mizowaki T, Sakamoto T, et al. Clinical outcomes of a phase I/II study of 48 Gy of stereotactic body radiotherapy in 4 fractions for primary lung cancer using a stereotactic body frame. Int J Radiat Oncol Biol Phys. 2005;63(5):1427-31.

7. Nagata Y, Hiraoka M, Shibata T, Onishi H, Kokubo M, Karasawa K, et al. Prospective trial of stereotactic body radiation therapy for both operable and inoperable T1N0M0 non-small cell lung cancer: Japan clinical oncology group study JCOG0403. Int J Radiat Oncol Biol Phys. 2015;93(5):989-96.

8. Chang JY, Senan S, Paul MA, Mehran RJ, Louie AV, Balter P, et al. Stereotactic ablative radiotherapy versus lobectomy for operable stage I non-small-cell lung cancer: a pooled analysis of two randomised trials. Lancet Oncol. 2015;16(6):630-7.

9. Ma L, Xiang J. Clinical outcomes of video-assisted thoracic surgery and stereotactic body radiation therapy for early-stage non-small cell lung cancer: a meta-analysis. Thorac Cancer. 2016;7(4):442-51.

10. Charlson ME, Pompei $P$, Ales KL, Mackenzie CR. A new method of classifying prognostic comorbidity in longitudinal studies: development and validation. J Chronic Dis. 1987;40(5):373-83.

11. Bush DA, Cheek G, Zaheer S, Wallen J, Mirshahidi H, Katerelos A, et al. High-dose hypofractionated proton beam radiation therapy is safe and effective for central and perlPFheral early-stage non-small cell lung cancer: results of a 12-year experience at Loma Linda University medical Center. Int J Radiat Oncol Biol Phys. 2013;86(5):964-8.

12. Register SP, Zhang X, Mohan R, Chang JY. Proton stereotactic body radiation therapy for clinically challenging cases of centrally and superiorly located stage I non-small-cell lung cancer. Int J Radiat Oncol Biol Phys. 2011;80(4):1015-22.

13. Chang JY, Komaki R, Wen HY, De Gracia B, Bluett JB, McAleer MF, et al. Toxicity and patterns of failure of adaptive/ablative proton therapy for early-stage, medically inoperable non-small cell lung cancer. Int J Radiat Oncol Biol Phys. 2011;80(5):1350-7.

14. Nihei K, Ogino T, Ishikura S, Nishimura H. High-dose proton beam therapy for stage I non-small-cell lung cancer. Int J Radiat Oncol Biol Phys. 2006;65(1):107-11.

15. Chang JY, Komaki R, Lu C, Wen HY, Allen PK, Tsao A, et al. Phase 2 study of high-dose proton therapy with concurrent chemotherapy for unresectable stage III nonsmall cell lung cancer. Cancer. 2011;117(20): 4707-13.

16. Kadoya N, Obata $\mathrm{Y}$, Kato $T$, Kagiya M, Nakamura T, Tomoda T, et al. Dose-volume comparison of proton radiotherapy and stereotactic body radiotherapy for non-small-cell lung cancer. Int J Radiat Oncol Biol Phys. 2011;79(4):1225-31.

17. Lee $\mathrm{CH}$, Tait $\mathrm{D}$, Nahum $\mathrm{AE}$, Webb S. Comparison of proton therapy and conformal X-ray therapy in non-small cell lung cancer (NSCLC). Br J Radiol. 1999;72(863):1078-84.

18. Suit H, Goldberg S, Niemierko A, Trofimov A, Adams J, Paganetti H. Proton beams to replace photon beams in radical dose treatments. Acta Oncol. 2003;42(8):800-8.

19. Moyers MF, Miller DW, Bush DA, Slater JD. Methodologies and tools for proton beam design for lung tumors. Int J Radiat Oncol Biol Phys. 2001:49(5):1429-38.

20. Common Terminology Criteria for Adverse Events (CTCAE) Version 4.0. Published May 28, 2009; Revised Version 4.03 June 14, 2010. [http://evs. nci.nih.gov/ftp1/CTCAE/CTCAE_4.03_2010-06-14_QuickReference_8.5x11. pdf. Accessed 20 Mar 2017

21. Dubray B, Henry-Amar M, Meerwaldt JH, Noordijk EM, Dixon DO, Cosset $J M$, et al. Radiation-induced lung damage after thoracic irradiation for Hodgkin's disease: the role of fractionation. Radiother Oncol. 1995;36(3): 211-7.

22. Tsujino K, Hashimoto T, Shimada T, Yoden E, Fujii O, Ota Y, et al. Combined analysis of V20, VS5, pulmonary fibrosis score on baseline computed tomography, and patient age improves prediction of severe radiation pneumonitis after concurrent chemoradiotherapy for locally advanced non-small-cell lung cancer. J Thorac Oncol. 2014;9(7):983-90.

23. Barriger RB, Forquer JA, Brabham JG, Andolino DL, Shapiro RH, Henderson MA, et al. A dose-volume analysis of radiation pneumonitis in non-small cell lung cancer patients treated with stereotactic body radiation therapy. Int J Radiat Oncol Biol Phys. 2012;82(1):457-62.

24. Nakagawa $T$, Negoro $Y$, Matsuoka T, Okumura N, Dodo Y. Comparison of the outcomes of stereotactic body radiotherapy and surgery in elderly patients with cT1-2N0M0 non-small cell lung cancer. Respir Investig. 2014;52(4):221-6.

25. Shirvani SM, Jiang J, Chang JY, Welsh JW, Gomez DR, Swisher S, et al. Comparative effectiveness of 5 treatment strategies for early-stage nonsmall cell lung cancer in the elderly. Int J Radiat Oncol Biol Phys. 2012; 84(5):1060-70.

26. Paul S, Lee PC, Mao J, Isaacs AJ, Sedrakyan A. Long term survival with stereotactic ablative radiotherapy (SABR) versus thoracoscopic sublobar 
lung resection in elderly people: national population based study with propensity matched comparative analysis. BMJ. 2016;354:i3570.

27. Titt U, Sell M, Unkelbach J, Bangert M, Mirkovic D, Oelfke U, et al.

Degradation of proton depth dose distributions attributable to

microstructures in lung-equivalent material. Med Phys. 2015;42(11):6425-32.

Submit your next manuscript to BioMed Central and we will help you at every step:

- We accept pre-submission inquiries

- Our selector tool helps you to find the most relevant journal

- We provide round the clock customer support

- Convenient online submission

- Thorough peer review

- Inclusion in PubMed and all major indexing services

- Maximum visibility for your research

Submit your manuscript at www.biomedcentral.com/submit 